\title{
The Loss of Diversity in the Anthropocene Biological and Cultural Dimensions
}

\author{
Thomas Hylland Eriksen * \\ University of Oslo, Oslo, Norway
}

\section{OPEN ACCESS}

Edited by:

Lorenzo Posocco,

University College Dublin, Ireland

Reviewed by:

Daniele Conversi,

IKERBASQUE Basque Foundation for

Science, Spain

Quentin Gausset,

University of Copenhagen, Denmark

*Correspondence:

Thomas Hylland Eriksen

t.h.eriksen@sai.uio.no

Specialty section: This article was submitted to

Comparative Governance,

a section of the journal

Frontiers in Political Science

Received: 19 July 2021

Accepted: 19 August 2021

Published: 06 September 2021

Citation:

Eriksen TH (2021) The Loss of Diversity in the Anthropocene Biological and

Cultural Dimensions.

Front. Polit. Sci. 3:743610.

doi: 10.3389/fpos.2021.743610
Theories of nationalism emphasise its standardising effects. Ernest Gellner compared the pre-nationalist world to a painting by Kokoschka (a colour extravaganza) and the world of nationalism as one by Modigliani (calm, monochrome surfaces), while Benedict Anderson showed how the standardisation of language through the medium of printing was a condition for shared national identities. In this article, homogenisation remains a concern, but the empirical framework differs from that of late 20th century theory. Taking its cue from Charles Mann's 1493, a study of the world after Columbus where the term Homogenocene was proposed, the article shows how homogenisation is a key element in modernity, and analyses some implications of its recent acceleration. The effects of economic globalisation are detrimental to both biological and cultural diversity, since the Anthropocene era does not only refer to a reduction of biological diversity but also the incorporation of cultural groups into market economies, the loss of languages and of traditional livelihoods. The article then briefly surveys some responses to the upscaling of economies, the flattening of ecosystems and the growing power of corporations. The loss of flexibility is countered in a number of ways, from attempts to restore damaged ecosystems to groups defending their cultural and political autonomy. The analysis argues for a broad definition of politics (seen as the political), thereby questioning the ability of the state to solve the dilemma, which is a dual one relating simultaneously to cultural and biological loss. The conclusion is that upscaling (e.g., to the global system) is usually part of the problem rather than the solution, and that sideways scaling may address the shortcomings of downscaling (e.g., to the community level).

Keywords: anthropocene, biological diversity, cultural diversity, biosemiotics, anthropology, political activism, homogenocene

\section{INTRODUCTION}

In a world consisting of more than two hundred sovereign states in competitive relationships, shared global challenges are difficult to deal with. Foremost among these are currently climate change and environmental destruction. An urgent question for scholars and policymakers concerns whether solutions are to be found by upscaling or downscaling; should more power be allocated to the United Nations; does the world need more strongly phrased or more binding climate agreements? Or are the proposed large-scale solutions rather part of the problem since they fail to take diversity and local agency into account, and usually come to naught since international treaties on climate have so far scarcely been followed up in practice? 
The aim of this article is to address the question how to respond effectively to the collective global challenge of anthropogenic climate change. I will give an account of the present world of overheated global modernity, its origins and some of its characteristics, with an emphasis on homogenisation as a central feature of the modern world. Both cultural and biological homogenisation, or tendencies towards monoculture, are described, and the parallels and differences between the "flattening" of cultural diversity and the impoverishment of ecosystems are shown to be results of imperial expansion and modern capitalism. The outcome will be analysed as a loss of semiotic freedom and flexibility. This dual process, it is subsequently argued, is frequently a result of upscaling, creating a growing gulf between life on the ground and the level of decision-making, as well as unintended consequences leading to global tragedies of the commons. I finally describe briefly some forms of resistance by identifying countermovements attempting to reinstate diversity, both in the realm of culture and in that of ecology. These attempts could come from indigenous groups, but just as easily from concerned middle-class people in the OECD or even startup businesses, but rarely from major corporations or governments. This is why the conceptualisation of politics in the present context has to move beyond institutional politics and look at the way in which political agency works in practice.

The parallels between biological and cultural diversity should not be exaggerated. The time scales differ enormously. Evolution is driven by "the blind watchmaker" (Dawkins 1986) of natural selection, while cultural differentiation relies on human consciousness and creativity. Yet, a comparison can be fruitful at this historical moment, when the homogenising forces of globalisation threaten and reduce both biological and cultural diversity. We may be witnessing a sixth extinction (Kolbert 2014) in nature, and it is estimated that only ten per cent of the roughly 6,000 languages spoken today are safe from extinction (Crystal 2014). Some estimates suggest that one language loses its last native speaker every 2 weeks.

Both processes have accelerated in the last few decades. Only four per cent of the mammalian biomass on Earth now belongs to wild animals (Elhacham et al., 2020). Seventy per cent of the birds in the world are domesticated, mainly poultry. The reduction of variation and of difference thus seems to apply both in the natural and the sociocultural world, often with similar causes and comparable results.

\section{THE HOMOGENOCENE}

Seen with the hindsight afforded by the world of the 21 st century, it is a striking fact that influential theories of modernity in the last century rarely included environmental destruction and climate change as major concerns. By contrast, a related feature of the contemporary world has been studied and theorised since the advent of social theory, namely homogenisation and standardisation as central features of modernity. The tendency of the modern state and the capitalist economy to iron out differences and create homogeneity has been necessary both at the political level (the nation-state, emerging in the 19th century, required cultural flattening) and in the world economy (which is increasingly globalised, often following Ricardo's principle of comparative advantage). The urbanisation and increased differentiation of modern societies in the North Atlantic world was already a major concern in late 19th century social theory. For example, Tönnies's distinction between Gemeinschaft and Gesellschaft ("community" and "society", Tönnies 1963[1889]) identified a shift in the mode of social organisation and value orientation, towards greater individualism and anonymity. Similarly, Durkheim's contrast between mechanical and organic solidarity (Durkheim 1997 [1883] referred to a transition from relatively undifferentiated rural societies to societies with an advanced division of labour, and the perhaps most celebrated of all classic social theorists-Marx and Weber-both wrote copiously on the implications of these radical transformations.

The reduction of cultural diversity as a result of colonialism and its accompanying modernisation was a concern already for early 20th century anthropologists, for example in W. H. R. Rivers (1922) anxiety over the assumed population decline in Melanesia and the "salvage anthropology" promoted in the United States by Franz Boas and his students, who were scrambling to save indigenous cultures from oblivion before they vanished, as they were predicted to do.

More recently, research on nationalism and globalisation has addressed questions of social and cultural homogenisation. Both Gellner (1983) and Anderson (1983) describe a historical moment in which a world of many small differences has been transformed to a world of just a few major ones, with Anderson referring to the standardising effects of print capitalism, Gellner to the implications of the industrial revolution. In a memorable allegory, Gellner compares the modern industrial world to a painting by Modigliani-large, calm, monochrome surfaces-contrasting it with a mainly agrarian world reminiscent of a painting by the expressionist Kokoschka, known for his intense use of colour.

A decade later, Castells (1996) wrote about the emerging global network society, which produces a common language for talking about both similarities and differences owing to intensified contact across borders. This situation was, incidentally, described almost avant la lettre by (McLuhan 1994 [1964]), who was nevertheless aware that "the global village" was not a peaceful place, but rather one fraught with friction and conflict of the kind described decades later by Barber (1995) as Jihad versus McWorld. Later still, Ritzer (2004) wrote about what he calls the globalization of nothing, which refers to generic phenomena with no discernable local provenance, spreading rapidly as a consequence of a flattening global modernity rendering everything comparable to everything else.

Such theoretical perspectives on the present era offer important insights into global cultural homogenisation and its accompanying frictions, but climate and the environment are conspicuously absent in all these analyses. By now, it is nonetheless difficult to speak credibly about the human condition under accelerated globalisation without recognising that environmental destruction and climate change are major 
issues and fundamental political challenges. This shift represents nothing less than a watershed: Speaking about international relations, global inequality, nationalism or economic globalisation without mentioning climate or the environment now seems about as dated as talking about development in the 1980s without a gender perspective.

A fifth into the twenty-first century, human domination of Earth is such that the term Anthropocene has become widespread as a general description. Since the onset of the industrial revolution in Europe, human activity and expansion have transformed the planet in unprecedented ways, and change continues to accelerate in a number of domains. This situation represents an escalating problem for all of humanity-indeed for all life on the planet. The challenges for research and theory are enormous, and the Anthropocene moment may well be seen retrospectively as a turning point in the social sciences and humanities (Mathews, 2020).

Ecological and environmental perspectives on politics and the human condition have never been absent, but they have become mainstream in the social sciences and humanities only recently. A reasonable starting-point for the current growth of theoretical and empirical literature on the Anthropocene could be the moment when the term itself was introduced around the turn of the millennium, coined independently by the atmospheric chemist Paul Crutzen and the biologist Eugene Stoermer. Crutzen was also the co-author of a much cited article, with his colleague Will Steffen and the historian John McNeill (Steffen et al., 2007), on social aspects of climate change. McNeill is the author, with Peter McNeill and Engelke (2016), of a book about "the great acceleration" since 1945, describing it mainly as one of human expansion and environmental destruction. In a recent review article, Syvitski et al. (2020) identify 1950 as the take-off point for the new epoch, showing rapid increase both in population and energy consumption from that year onwards. In the last couple of decades, the literature on climate, the environment and the human condition has grown exponentially in the humanities and social sciences. However, few have paid systematic attention to the implications of the dual process of ecological and cultural homogenisation. In one of the few studies which takes on the drive to homogeneity in both domains, Charles Mann (2011) coined the term The Homogenocene as a label for the modern world, characterised by unprecedented, and accelerating, flows of people, pests, crops, and forms of political domination. Mann takes a longue durée perspective on homogenisation, arguing that the seeds of the current era of monocultures, species extinction and invasion, language death and ubiquituous consumerism were sown at the time of the European conquests, and tellingly, the book introducing the term Homogenocene is titled 1493.

Global homogenisation has gained pace since its beginning at the start of the Columbian exchange (Crosby 2003 [1972]). China, in important respects culturally quite distinct from the North Atlantic world, is now competing on a par with the latter in the global economy, and Chinese citizens seem to be no less devoted to consumption of manufactured goods than Westerners. Comparability along several axes becomes more feasible than in a past when cultural differences overshadowed the emerging similarities.

\section{ENERGY: THE TRIPLE BIND}

This is about politics in the Anthropo- or Homogenocene, and energy is a key factor. Perhaps the most influential interdisciplinary writer on energy is Václav Smil (Smil 2017), who takes a historical, comparative and contemporary view on energy. His analysis of energy transitions, especially of the shift from muscle power to machinery, makes it possible to understand why megacities have become possible in the present era, since the size of pre-modern cities was limited by the supply of energy, which had to be produced by people and beasts of burden. Energy is also a key factor in the loss of flexibility characterising our era. A society committed to high energy use can only with great difficulty, and with painful sacrifices, return to a low-energy society. Like language, money and mechanical time, energy renders societies comparable by producing a shared set of parameters for evaluating them (these days both in terms of development/affluence and in terms of ecological sustainability). A focus on energy also indicates the difficulties of Anthropocene challenges. As shown by many scholars, most recently Vogel et al. (2021), the correlation between energy use and life satisfaction is clear if not unanimous. There can be no easy transition from a high-energy society to a sustainable one, especially in light of the rapid global population growth of the last two centuries (Wilhite 2016; Hoff, Gausset, and Lex 2019).

The archaeologist Joseph Tainter has analysed the causes of civilizational collapse in the past (Tainter 1988, Tainter 2014), a perspective subsequently popularised by Jared Diamond (2005). Tainter indicates ways in which contemporary societies can learn from archaeological research when faced with urgent or simmering crises. In his comments on the present, which draw heavily on the collapse of the Roman and Maya empires, environmental destruction comes across as just one factor in accounting for the decline of complex societies. In his view, the decisive cause consists in decreased marginal returns on investments in energy (EROI), owing to population growth and subsequent intensification of food production with decreasing returns, coupled with growth in bureaucratic, logistic and transport costs. Since the late 18th century, we have been able to exploit enormous amounts of energy, at first just in the shape of abundant and easily accessible coal deposits, subsequently through the exploitation of oil and gas for the betterment of humanity. The fossil fuel revolution enabled us to support a fast growing global population with seemingly insatiable desires for consumption. Yet the cost of taking out fossil fuels increases as the low-hanging fruit is being depleted. At the same time, production relying on fossil fuels is tantamount to destruction (Hornborg 2019), in a dual sense, since we are simultaneously eating up capital which it has taken the planet millions of years to produce, and are undermining the conditions for our own civilization by altering the climate and ruining the environment on which we rely. We are entangled in a triple bind, a wicked trilemma where sustainability, growth and reliance on fossil fuels cannot be reconciled: only one of the three is possible (see Bateson et al., 1956 on the double bind).

Coal and its close relatives oil and gas, the salvation of humanity for two centuries, are now becoming our 
damnation, and there is no easy way out. The lesson from cultural history may nevertheless be that lean societies, decentralised and flexible, with less bureaucracy than farming, fewer PR people than fishermen, are the most sustainable in the long term, and to this possibility I shall return. As Tainter remarks: "Complex societies ... are recent in human history. Collapse then is not a fall to some primordial chaos, but a return to the normal human condition of lower complexity" (Tainter 1988: 198). This is an insight with potential implications for a politics of the Anthropocene.

\section{OVERHEATING AS A CONDITION FOR THE HOMOGENOCENE}

A further elaboration of Anthropocene effects may apply the concept of overheating in order to interrogate the acceleration of acceleration since the end of the Cold War and the coming of the Internet and mobile telephony, around 1990, where changes in a number of interrelated domains have taken off at ever increasing speed-from urban growth in the Global South and international trade to mining and international travel (Eriksen 2016; Erisken 2018).

The current human population of nearly eight billion (compared to one billion in 1800 and just two billion as late as 1920) travels, produces, consumes, innovates, communicates, fights and reproduces in a multitude of ways, and we are increasingly aware of each other as we do so. The steady acceleration of communication and transportation in the last two centuries has facilitated contact and made isolation difficult, and is weaving the growing global population ever closer together, affecting cultural differences, local identities and power relations. Indeed, as decades of research on collective identification has shown, intensified identity management and the assertion of group boundaries is a likely outcome of increased contact and perceived threats to group integrity. A general formula is that the more similar we become, the more different we try to be, although it could be added that the more different we try to be, the more similar we become, since there is a shared global grammar for the effective expression of uniqueness. The standardization of identity currently witnessed in nationalism and religious revivalism is a feature of modernity, not of tradition, although it tends to be dressed in traditional garb. Tradition is traditional, but traditionalism is modern.

Ranging from foreign direct investments and the number of internet connections to global energy use, urbanisation in the global south and increased migration rates, rapid transformations impact social life in many ways, and have in some respects visibly stepped up their pace since the 1990s. Dramatic alterations to the environment, economic transformations and social rearrangements are the order of the day in so many parts of the world, and in so many areas, that it may not be hyperbole to speak of the global situation as being overheated.

Overheating does not merely designate climate change. In physics, heat is simply a synonym for speed, and translated into the language of social science, overheating can refer to fast change. The changes brought about by modernity have unintended, often paradoxical consequences, and when changes accelerate, so do the unintentional side-effects of changes. The term overheating calls attention to both accelerated change and the tensions, conflicts and frictions it engenders, as well as-implicitly-signalling the need to examine, through dialectical negation, the possibility of deceleration or cooling down. Generally speaking, when things are suddenly brought into motion, they create friction; when things rub against each other, heat is generated at the interstices. Heat, for those who have been caught unawares by it, may result in torridness and apathy, but it may also trigger a number of other transformations, the trajectories of which may not be clear at the outset. When water is brought to the boiling point, for instance, it changes into a different substance. In a similar fashion, we arguably find ourselves at a "systemic edge" these days, as economic, as social and cultural forms of globalisation are expanding into ever new territories, often changing the very fundamentals of customary life for those who find themselves taken in by the whirlwinds of change. These processes are not unilaterally negative or positive for those affected by them, since what may be perceived as a crisis by some could very well represent positive opportunities to others, and the potential for spontaneous transformative moments is always present. Even climate change is sometimes welcomed, for example in cold regions where agriculture becomes feasible, or even further north, where the melting of the Arctic ice creates exciting opportunities for oil companies and may lead to the opening of new shipping routes. Overheating consists in a series of unintended, and interrelated, consequences triggered by global neoliberal deregulation, technological developments rendering communication instantaneous and transportation inexpensive, increased energy consumption, and a consumerist ethos animating the desires of a growing world population.

One significant aspect of overheating is the lack of a thermostat or governor. There is no instance which has the authority to order the Anthropocene world to cool down owing to its destructive effects. As a result, runaway competition continues to escalate, notwithstanding the sudden break caused by the Covid-19 pandemic. This is one reason why a sustainable politics of the Anthropocene urgently needs to be theorised and conceptualised.

Overheating can be identified in many domains. Tourism has increased sixfold since the late 1970s, from 200 million to more than 1.2 billion international tourist arrivals annually in 2019. Global energy consumption, which has increased by a factor of thirty since Napoleon Bonaparte's exile, has doubled since 1975. Capitalism, globally hegemonic since the nineteenth century, is now becoming universal in the sense that scarcely any human group now lives completely independently of a monetised economy. Traditional, often communal forms of land tenure are being replaced by private ownership, subsistence agriculture is being phased out in favour of industrial food production, siphoning former peasants into the informal sector in cities; the affordances of the smartphone replace orally transmitted tales, and by 2007 , more than half of the world's population lived in urban areas. By the middle of this century, the proportion may be seventy per cent. The state by now enters into people's lives almost everywhere, though to different 
degrees and in different ways, and individual states have proved incapable of addressing the burning issues to do with ecological crises and climate change.

\section{PLANTATIONOCENE}

The overheated Anthropocene was not an inevitable outcome of 1493. Other trajectories are easily imaginable. Nonetheless, the convergence and mutual reinforcement of the scientific revolution after the Renaissance, the economic growth in the imperial centres resulting from increased trade and pillage, slavery and plantations, technological advances resulting at least partly from competition between the early modern European states and the incipient secularisation leading to faith in progress and development replacing Christian dogma, encouraged the growth of a capitalist world economy, as famously analysed by Wallerstein (1974-79) and-seeing it from the perspective of the colonised-Wolf (1982). The plantation, described by Mintz (1985) as a "proto-factory" based on standardisation, mass production and the disposability of labourers, contributed massively to the economies benefiting from it. The great homogenisation was under way.

For centuries, species of plants and animals were deliberately introduced to the colonies (and elsewhere-silkworms were smuggled out of China as early as the sixth century CE). Tropical botanical gardens were experimental sites for exploring agricultural potential. Cattle were shipped to Argentina, maize to East Africa, sugar cane to the Caribbean and so on. Only in the last few decades have introduced species come to be seen as a problem rather than a solution.

Species have migrated since the beginning of life on Earth, and - to note the parallel with cultural diversity-cultures have influenced each other since we started making abstractions many thousand years ago. The field of biogeography is the study of the dissemination of species in evolutionary time, and barriers such as mountain ranges, climatic zones and open stretches of ocean have been of particular interest. In oceanic islands, and in the isolated continent Australia, evolution could take separate paths. The giant tortoises in Galápagos, the dodo in Mauritius and the Komodo dragon on a handful of Indonesian islands could thrive for millions of years in the absence of competition or devastating predation. The temporal axis of cultural history is much shorter, but the patterns are comparable. In dense forests, barren semideserts and narrow mountain valleys, cultural forms evolved which long had limited contact with the outside world. In New Guinea, mountainous and forested, horticulture has probably been practised as long as grain production in Mesopotamia. When Europeans arrived in its highlands less than a century ago, it appeared to them as if time had stood still. Headhunting remained widespread, metals were unknown, and several hundred languages were spoken, most of them unrelated to all other languages. Along the northern coast, where there had been continuous contact with traders, pirates, castaways and eventually missionaries and colonial administrators, the situation was different. Most of the inhabitants spoke Austronesian languages, related to other languages from Madagascar to Rapa Nui. The ocean has always been a road, both biologically and culturally speaking, its islands and ports crossroads and hubs of migration, hybridisation, creolisation, and exchange.

This road was macadamised and turned into a smooth highway in the centuries following 1492. Eventually, the territorial expansions of animals and plants on land, natural rafts and migratory birds were no longer needed for species to spread. Human migrations might now take the form of transatlantic slavery, enforced labour in silver mines and movement into growing cities both in and outside of Europe. States and empires took shape worldwide, and they increasingly began to resemble each other, especially after the First World War. Again, it needs to be pointed out that such exchanges and movements existed before 1492 as well; one may only think of the trade networks of the Roman empire or the slave raids of the Moors. Yet, the scope, extent and velocity of these exchanges started to increase, with serious unintended side-effects for people and nature.

Since the end of the Cold War, it is as if all speed limits on the global highways have been abandoned. Changes now take place at a rate making it difficult for researchers and commentators to follow them; for example, climate change projections are uncertain and are continuously being modified.

In 1493, Mann devotes a great deal of attention to food production, and one of his concerns is the reduction of biological diversity in an era dominated by the logic of the factory and the plantation, where the entire world is considered a market. When an oil palm plantation replaces a rainforest, not only do a variety of trees of different species disappear, but so do microorganisms, insects, the birds feeding on the insects, rodents, lizards, a diverse undergrowth and the fungal networks helping to sustain the forest. The soil composition changes, and the entire biotope is simplified and standardised. I am writing this in a cabin on the south-eastern coast of Norway, where the cod, until recently ubiquituous, has all but been driven to extinction locally. At the same time, fish farming - the cotton plantations of the sea-is booming.

A similar objection as that directed to plantation monoculture was raised against industrially produced goods in the nineteenth century, when guilds and connoisseurs criticised them for being simplified, identical and bland. Yet mass production turned out to be profitable, commodities became cheaper, and the standard of living improved.

The green revolution in agriculture has led to comparable effects. Productivity has increased, mass starvation has nearly been eradicated in large countries like India, but the price to pay is a loss of diversity and flexibility.

In The McDonaldization of Society, Ritzer (first ed. 1993) argues along the same lines, updating Weber on rationalisation. He describes a world of production and consumption where upscaling, simplification and standardisation dominate. Large chains outcompete smaller businesses, and common denominators rule because they generate the most revenue.

In the realm of culture, it is more difficult to measure diversity than in biology. Ritzer refrains from an assessment of entire 
life-worlds, limiting himself to observable consumption. Many scholars of consumption have argued, contrary to the McDonaldisation thesis, that consumers are creative and independent, and that apparent standardisation conceals great variation. This view is not irrelevant, but it remains indisputable that the new diversity is different from the old. If it can reasonably be claimed that each language conjures up a world with some unique features, predictions of language death suggest that the cultural diversity in the world is faced with a mass extinction comparable to the observable reduction in biological diversity.

\section{WHAT OF THE NEW DIVERSITY?}

The claim that cultural diversity in the world is being reduced demands a closer examination. For is it not a fact that precisely this moment of accelerated globalisation produces a plethora of new cultural forms owing to transnational communication and migration?

The concept super-diversity has been suggested, by Vertovec (2007), in order to describe the diversification of diversity, especially as it can be observed in cities, the cultural crossroads par excellence. His observation is valid, and it is true that new identities are continuously being produced-religious, ethnic or post-ethnic, pertaining to gender-but they tend to conform to a uniform, global grammar. Across the world, there are people who emphasise their uniqueness, but they usually do so in the same ways, conforming to individualism, consumerism and choosing among the alternatives on offer in the supermarket of individual choice.

Ethnicity does not result from cultural differences, but amounts to ideologies of cultural difference. Ethnicity consists in making cultural differences comparable, meaning that in order to communicate their difference, people must first attune themselves to a transcultural conversation about cultural difference. Before the Homogenocene, different peoples could be unintelligible to each other. In Tristes Tropiques, (Lévi-Strauss 1976 [1955]) describes an encounter with a Brazilian indigenous group in the 1930s as if there were an invisible glass wall between them: They could see each other, but communication was impossible.

The great leveller of modernity, producing what Gellner (1983) spoke of as cultural entropy, enables communication and comparison. Formerly, the other could come across like Wittgenstein's lion: If it could talk, we would not understand what it said.

The reduction of diversity is not without its benefits. While it did reduce crop diversity, the Green Revolution saved millions of lives by concentrating on a few, highly productive cereals. The advantages of using English as an international language are similarly obvious, and arguably enables many to expand rather than limit their cultural repertoire. The new forms of diversity led Hannerz to argue, in a rejoinder to Gellner, that a "return of Kokoschka" (Hannerz 1996) had taken place in the new, diverse cultural settings. Similarly, invasive species have sometimes found vacant niches and led to an increased diversity in local ecosystems (Thompson 2014).

At the same time, the underlying grammar is simplified and standardised. In the realm of culture, the anthropologist Clifford Geertz memorably quipped: "[C]ultural difference will doubtless remain - the French will never eat salted butter. But the good old days of widow burning and cannibalism are gone forever." (Geertz 1984: 105).

The UNESCO did not see this distinction when they produced the report Our Creative Diversity (UNESCO 1995). The authors celebrated cultural diversity while at the same time promoting a global ethics. Everybody should, in other words, be encouraged to be different and unique, but only in so far as they followed the established rules. They had to become similar in order for their uniqueness to be legitimate. Handicrafts, yes. Headhunting, no.

In a manner resembling the new cultural diversity, biological diversity is being safeguarded in national parks, zoos, and seed banks, but outside the reserves, the tendency is unequivocal. The loss of variation is undisputable both as regards culture and biology. This reduction of options leaves us with reduced flexibility, and the systemic effects are potentially catastrophic.

\section{EXTINCTIONS}

History never has a single direction, unless imposed by historians. Different parts of a culture change at different speeds. Norwegians will continue to be devoted to the outdoor life, and in Melanesia, people will still sacrifice pigs to the ancestors, although they now have smartphones and take part in a monetary economy. It may well be the case that English suppresses many small languages, but as a compensation, the English language becomes richer and more diverse, with many local variants and dialects. Yet there are striking parallels between descriptions of species extinction and biodiversity loss, as detailed in Kolbert's celebrated The Sixth Extinction (Kolbert 2014), and the situation for cultural diversity today, not least as regards small, stateless groups. It is true that indigenous people have never lived in total isolation, but the speed and comprehensiveness of the present encompassment by the forces of globalisation are unprecedented in history.

Kolbert identifies a series of causes for what she speaks of as the sixth extinction, taking lessons from the previous five extinctions as she goes along (the most famous of which was the temporary cooling of global climate following a meteor crashing on Yucatán, 66 million years ago, and leading to the extinction of the dinosaurs).

Some of the causes of extinction described by Kolbert are species invasion, habitat loss or fragmentation, overexploitation of natural resources and natural disasters, but the most important cause, related to some of the others, is anthropogenic ecological destabilisation, that is pollution and climate change.

Parallels can be drawn between Kolbert's analysis of biodiversity loss and processes affecting people and their cultural worlds. Habitat loss resembles the effects of "accumulation by dispossession" (Harvey 2003) whereby people lose their homes and livelihood owing to large-scale 
infrastructural developments, becoming urbanised or proletarianised because there is no other option available. Overexploitation of resources also deprives indigenous people of their livelihood, and species invasion may have a parallel in the homogenising effects of states and markets. Climate change, needless to say, affects people as well as the rest of nature (UNEP, 2021).

Culture has a different internal dynamics than biology, but this should not detract attention from the parallels. Benevolent state policies on indigenous matters resemble the thinking behind national parks. State control and the relentless desire to translate everything to measurable and profitable "resources" in the corporate world contribute to upscaling and homogenisation in both realms. The benefits of homogenisation are gauged with the universal standards of modernity: Economic growth, improved access to education, reduced child mortality, improved sanitation and so on. Not everybody benefits. Some are faced with the bill without having had the chance to reap the benefits. Ultimately, everybody loses because future options are narrowed and we are collectively painting ourselves into a corner. The greatest loss, seen from a long-term global perspective, is the loss of flexibility. The insistence on a single economic system presupposing eternal growth, a few highly productive food crops and, not least, the destructive and potentially catastrophic reliance on fossil fuels, leads to a game with high stakes and one that cannot be won in the long term.

A potentially fruitful way of conceptualising this situation is by analysing it as one of reduced semiotic freedom.

\section{SEMIOTIC FREEDOM AND THE HOMOGENOCENE}

A pioneer in the emerging field of biosemiotics, Jesper Hoffmeyer had a suitably interdisciplinary background in chemistry, biology, philosophy, and semiotics. In biosemiotics, relationships in nature are interpreted as acts of communication. When a fox becomes aware of a hare in the vicinity, its reaction forms part of a semiotic chain together with the hare's response and flight, the hunt and its outcome. Hoffmeyer once said that if he were to summarise the entire history of evolution in one sentence, he would say that evolution has, over the millions of years, led to an overall growth in semiotic freedom (Hoffmeyer 1998). Allow a short explanation.

All organisms have a certain degree of semiotic freedom, that is an ability to respond to their environment in different ways. A plant may stretch towards the sunlight or direct its roots to the most nutritious parts of the soil; some plants do not, and they lose. A dog may play with its owner and pretend to bite her; in other words, it is capable of meta-communication (Bateson 1972). The relationship between human and dog releases a greater semiotic freedom-more alternatives, greater depth in signification, more flexibility-than the relationship between a pine tree and the mushrooms and ferns growing beneath it, although an exchange of signs and responses also take place in the latter case. Hoffmeyer thus describes an evolutionary movements towards more complexity, more communication, more relationships and a denser forest of signs sending a growing number of messages in a hierarchy of logical levels.

A reading of biosemiotics which connects it to the homogenising effects of globalisation described in this article makes it possible to conclude that the development is now being reversed. The beginning of the modern environmental movement was marked by the publication of Rachel Carson's The Silent Spring (Carson 1962), the opening gambit of which is the observation that the songbirds were gone. Similarly, in oral African cultures it is said that when an old tribesman dies, it is as if a library is burnt down.

Hoffmeyer does not mention the five mass extinctions in evolutionary history, which must have led to a temporary reduction in semiotic freedom, but his argument is nevertheless an important one. It can be applied to the cultural history of humanity. Since the origin of homo sapiens in Africa around 250,000 years ago, groups have branched off, diversified, adapted to and developed viable niches in all biotopes except Antarctica. Thousands of mutually unintelligible languages, unique religions and customs, kinship systems, cosmologies and economic practices produced a world of a fast growing number of differences. What seems to be happening today as a result of frantic human activity across the planet is nevertheless a reduction in semiotic freedom, a loss of flexibility and options. This seems to be the case both with respect to the nonhuman world and that of culture and society.

This means that if Hoffmeyer's view has been correct up to the near-present, it now seems that we shall have to reconcile ourselves with a world with decreasing semiotic freedom, both in the cultural and the biological domains. The political challenge consists in halting this movement away from a world of many little differences to one of a few major ones, and thus, it may be argued that a concern with biological diversity and cultural diversity are two sides of the same coin.

\section{FROM TINA TO TAMA: SCALING POLITICS OF THE ANTHROPOCENE}

The political agents resisting the Homogenocene are of a different kind to those typically studied by political scientists. Since the reduction of diversity is caused by governments and corporate interests, it is necessary to look elsewhere for resistance movements. I shall briefly describe some of them, indicating that although they may have comparable objectives, they work in different settings and on different scales. The plurality of movements working to retain local autonomy and healthy ecosystems effectively falsifies the TINA (There Is No Alternative) doctrine popularised in the 1980s by Margaret Thatcher by showing that in fact, TAMA (There Are Many Alternatives).

One such proposed alternative is rewilding. Rewilding Europe, an NGO starting in 2011, has partnered with governments and sponsors with the aim to restore ecosystems that have been affected by global homogenisation. Currently, Rewilding Europe has eight active projects, from Portugal to Swedish 
Lapland. Restoration of ecosystems also takes other forms, and it is practised on many scales. In Tasmania, for example, civil society volunteers spend Sundays removing invasive shrubs-some of which were deliberately imported for their beauty as late as the 1970s-from the landscape, trying to strengthen the relative position of endemic plants. Further north, in Queensland, "toadbusting" is an organised activity for volunteers in many locations, where the aim is to curb the spread of the deliberately imported, but now invasive and destructive, cane toad, originally a Central American species. On a slightly larger scale, the transformation of South African farms into game parks has led to the reintroduction of animals-mainly herbivores, but also big cats in a few cases-to regions where they had been driven to extinction in historical times. An unknown concept at the turn of the millennium, rewilding is now being recognised as a tool of what we might call "salvage ecology".

The greater semiotic freedom of humans, compared to other species, entails above all self-consciousness and reflexivity. Hence, although the European bison (part of a rewilding project) cannot represent itself-it must be represented-people can, and they do. Lien (2021) describes a court case concerning land rights in northern Scandinavia, involving the Norwegian state and Sami reindeer herders. One of the herders, called as a witness in court, was asked to identify the location of his migratory route on a map. $\mathrm{He}$ refused, explaining its location instead by describing geographical and topological features, affirming that he had never needed to use maps. The literature on Sami ways of engaging with the world is substantial, much of it written by Sami scholars who thus function as cultural brokers. Sami land rights activists emphasise traditional forms of stewardship based on tradition rather than law, and many Sami also show a different way of relating to their environment, a different cosmology and view of social relations than that which is dominant in majority Nordic society (Eriksen et al., 2019).

Other indigenous groups are in a weaker bargaining position. Wilhite and Salinas (2019) have showed how indigenous groups in South America as well as India receive the sharp end of the stick threefold: by being deprived of their land and livelihood, by losing their option of cultural reproduction, and as victims of climate change. There are nevertheless positive examples from the Global South as well of indigenous groups mobilising successfully to retain their right to define and govern themselves. The most famous example is probably that of the Yanomami in Brazil, who were given rights to a territory of 99,000 square kilometres (twice the size of Denmark) by the Brazilian government in 1992. In recent years, the autonomous territory has nonetheless been invaded by thousands of garimpeiros, goldminers, with the tacit support of the Bolsanaro government.

Another form of resistance, described by Conversi (2021), is represented by faith-based communities such as Amish, who actively choose to stay aloof from mainstream capitalist state society. Both small-scale indigenous groups and these alternative communities (ecovillages could also be mentioned) are downscaled politically, with limited participation in the monetary economy, and they are ecologically sustainable. Hendry (2014), an anthropologist, has surveyed small-scale stateless societies with a view to glean insights into the kind of ecological thinking and practice that could contribute to changing the course of history away from certain catastrophe.

Yet considering the size and complexity of the human population (36 per cent of the planetary mammalian biomass is now human), there can be no return to the Garden of Eden, which does not mean that there are not useful lessons to be learned from indigenous cosmologies and small-scale countercultures. Significantly, all attempts to reinstate some of the lost diversity has an element of downscaling. For example, Conversi and Hau (2021) present and compare left-leaning secessionist parties in European countries, notably Scotland and Catalonia, which are favourable to radical climate policies. They identify a shift from a national romanticism glorifying the purity and authenticity of local nature to a pragmatic, concrete and demanding climate policy for the present.

The final example is that of the Creole Garden project in the Seychelles, where cultural specificity and biodiversity are at play simultaneously. A pilot project funded by the UNESCO, the Creole Garden aims to recover knowledge about crops and foods that can be grown locally. Ironically, the Creole garden arose from plantation slavery, but as a side-effect deemed uninteresting by the plantation owners, but essential for the slaves, who grew a variety of crops on their tiny plots for subsistence.

However, as the project proposal explains, and I quote it at some length, with modernity and the advent of supermarkets and flats and housing estates replacing the traditional creole community, the Creole Garden has lost ground and is not being transmitted to the younger generation.

And yet, the Creole Garden provides sustenance, traditional creole culinary skills and ingredients which are the basis of the celebrated creole cuisine in tourism, as well as medicinal plants that reduce the need to go to the doctor. During the Covid-19 lockdown period in Seychelles, our dependency on imported goods became glaringly clear as planes suddenly reduced to essential cargo, and certain fresh vegetables that were flown in every day became scarce. People started planting in pots if they lived in flats, and those who had land began planting typical creole foodstuff such as plantains, dessert bananas, yam, sweet potatoes, tomatoes and herbs.' (University of Seychelles 2021).

The Creole garden project brings many of the strands of the argument together. 1) It came about-somewhat ironically-as an unintentional effect of plantation slavery and the beginnings of the Homogenocene. 2) It rejects quests for purity, instead focusing on what works in the local ecology regardless of its origins. 3) It is small scale, scaled down to the household level. 4) The Creole garden combines a concern with biodiversity with the objective of saving Creole culture from oblivion at a time of Netflix and the smartphone. 5) The project is critical of the homogenising tendencies of large-scale production and distribution; in effect, it seeks to replace tinned food, imported mangoes and carrots with locally grown produce. This kind of project may well turn out to be an exemplar for a politics of the Anthropocene.

The question I have raised in this article concerns politics, specified as the political, engaging not with established political 
institutions, but rather political actions and projects engaged in by activists, NGOs and citizens wishing to contribute to political change. Since the contradictions of the overheated Homogenocene are the collateral damage of the state and the globalised fossil fuel economy, solutions must be sought elsewhere. This should not be taken to mean that only localised, or even grassroots movements are the only viable alternative. International agreements such as the ambitious UN Convention on Biological Diversity can be significant, but as the negative experiences of the Kyoto Agreement indicate, they are worthless unless implemented, and most governments have chosen not to do so. For this reason, a politics aiming to counteract the destructive effects of the global fossil fuel industry and the accompanying impoverishment of the biosphere and cultural diversity of the planet should mainly aim to scale down, but sideways scaling through networks of localised initiatives is also a highly relevant option, which can now be

\section{REFERENCES}

Anderson, B. (1983). Imagined Communities. An Inquiry into the Origins and Spread of Nationalism. London: Verso.

Barber, B. (1995). Jihad versus McWorld: How Globalism and Tribalism Are Reshaping the World. New York: Ballantine.

Bateson, G., Jackson, D. D., Haley, J., and Weakland, J. (1956). Toward a Theory of Schizophrenia. Behav. Sci. 1, 251-264. doi:10.1002/bs.3830010402

Bateson, G. (1972). Steps to an Ecology of Mind. New York: Bantam.

Castells, M. (1996). The Rise of the Network Society. Oxford: Blackwell.

Conversi, D. (2021). Exemplary Ethical Communities. A New Concept for a Livable Anthropocene. Sustainability 13, 5582. doi:10.3390/su13105582

Conversi, D., and Hau, M. F. (2021). Green Nationalism. Climate Action and Environmentalism in Left Nationalist Parties. Environ. Politics. doi:10.1080/ 09644016.2021.1907096

Crosby, A. (2003). The Columbian Exchange: Biological and Cultural Consequences of 1492. Westport, CT: Praeger.

Crystal, D. (2014). Language Death. Cambridge: Cambridge University Press.

Dawkins, R. (1986). The Blind Watchmaker. Why the Evidence Of Evolution Reveals a Universe Without Design. New York: Norton.

Diamond, J. (2005). Collapse: How Societies Choose to Fail or Succeed. New York: Viking.

Durkheim, E. (1997). The Division Of Labour In Society, Trans. W. D. Halls. New York: Free Press.

Elhacham, E., Ben-Uri, L., Grozovski, J., Bar-On, Y. M., and Milo, R. (2020). Global Human-Made Mass Exceeds All Living Biomass. Nature 588, 442-444. doi:10.1038/s41586-020-3010-5

Eriksen, T. H. (2018). An Overheated World. London: Routledge.

Eriksen, T. H. (2016). Overheating: An Anthropology of Accelerated Change. London: Pluto.

Eriksen, T. H., Valkonen, J., and Valkonen, S. (2019). Knowing from the Indigenous North: Sami Approaches to History, Politics and Belonging. London: Routledge.

Geertz, C. (1984). Distinguished Lecture: Anti Anti-relativism. Am. Anthropologist 86 (2), 263-278. doi:10.1525/aa.1984.86.2.02a00030

Gellner, E. (1983). Nations and Nationalism. Oxford: Blackwell.

Hannerz, U. (1996). Transnational Connections. London: Routledge.

Harvey, D. (2003). The New Imperialism. Oxford University Press.

Hoff, J., Gausset, Q., and Lex, S. (2019). Building a Sustainable Future: The Role of Non-state Actors in the green Transition. London: Routledge.

Hoffmeyer, J. (1998). Semiosis and Biohistory: A Reply. Semiotica 120 (3/4), 455-482. doi:10.1515/semi.1998.120.3-4.455

Hornborg, A. (2019). Nature, Society, and Justice in the Anthropocene: Unraveling the Money-Technology-Energy Complex. Cambridge: Cambridge University Press.

Kolbert, E. (2014). The Sixth Extinction: An Unnatural History. New York: Holt. achieved, somewhat paradoxically, by means of the very same electronic technology which is also a powerful cause of standardisation.

\section{DATA AVAILABILITY STATEMENT}

The original contributions presented in the study are included in the article/Supplementary Material, further inquiries can be directed to the corresponding author.

\section{AUTHOR CONTRIBUTIONS}

The author confirms being the sole contributor of this work and has approved it for publication.

Lévi-Strauss, C. (1976). Tristes Tropiques, Trans. John Weightman and Doreen Weightman. Harmondsworth: Penguin.

Lien, M. E. (2021). "On Not Using Maps; Colonising Practices and Modes of Knowing in Finnmark, Northern Norway,". Paper presented at the workshop 'The New Commons' (Oslo: Department of Social Anthropology). May 2021.

Mann, C. C. (2011). 1493: Uncovering the New World Columbus Created. New York: Vintage.

Mathews, A. S. (2020). Anthropology and the Anthropocene: Criticisms, Experiments, and Collaborations. Annu. Rev. Anthropol. 49, 67-82. doi:10.1146/annurev-anthro-102218-011317

McLuhan, M. (1994). Understanding Media: The Extensions of Man. London: Routledge.

McNeill, John. R., and Engelke, P. (2016). The Great Acceleration. Cambridge, MA: Harvard University Press.

Mintz, S. W. (1985). Sweetness and Power: The Place of Sugar in Modern History. Harmondsworth: Penguin.

Ritzer, G. (2004). The Globalization of Nothing. London: Sage.

Ritzer, G. (1993). The McDonaldization of Society: An Investigation into the Changing Character of Contemporary Social Life. Newbury Park, CA: Pine Forge Press.

Rivers, W. H. R. (1922). Essays on the Depopulation of Melanesia. Cambridge: Cambridge University Press.

Smil, V. (2017). Energy and Civilization: A History. Cambridge, MA: MIT Press.

Steffen, W., Crutzen, P. J., and McNeill, J. R. (2007). The Anthropocene: Are Humans Now Overwhelming the Great Forces of Nature. AMBIO: A J. Hum. Environ. 36 (8), 614-621. doi:10.1579/0044-7447(2007)36[614:taahno] 2.0.co;2

Syvitski, J., Waters, C. N., Day, J., Milliman, J. D., Summerhayes, C., Steffen, W., et al. (2020). Extraordinary Human Energy Consumption and Resultant Geological Impacts Beginning Around 1950 CE Initiated the Proposed Anthropocene Epoch. Commun. Earth Environ. 1, 32. doi:10.1038/s43247020-00029-y

Tainter, J. A. (2014). Collapse and Sustainability: Rome, the Maya, and the Modern World. Archeological Pap. Am. Anthropological Assoc. 24, 201-214. doi:10.1111/apaa.12038

Tainter, J. A. (1988). The Collapse of Complex Societies. Cambridge: Cambridge University Press.

Thompson, K. (2014). Where Do Camels Belong? the Story and Science of Invasive Species. London: Profile.

Tönnies, F. (1963). Community and Society. New York: Harper \& Row.

UNEP (2021). Convention on Biological Diversity. Available at: https://www.cbd. int/convention/text/ (Accessed July 18, 2021).

UNESCO (1995). Our Creative Diversity. Paris: UNESCO. 
University of The Seychelles (2021). Intangible Cultural Heritage Case Study Seychelles: Supporting Research and Documentation of Indigenous Knowledge Systems on Biodiversity Conservation, Climate Change and Disaster Risk Reduction in Eastern Africa. Unpublished Project Proposal. Anse Royale: University of Seychelles.

Vertovec, S. (2007). Super-Diversity and its Implications. Ethnic Racial Stud. 30 (6), 1024-1054. doi:10.1080/01419870701599465

Vogel, J., Steinberger, J. K., O'Neill, D. W., Lamb, W. F., and Krishnakumar, J. (2021). Socio-economic Conditions for Satisfying Human Needs at Low Energy Use: An International Analysis of Social Provisioning. Glob. Environ. Change 69, 102287. doi:10.1016/j.gloenvcha.2021.102287

Wallerstein, I. (1974). The Modern World-System (3 Vols). New York: Academic Press.

Wilhite, H. (2016). The Political Economy of Low Carbon Transformation: Breaking the Habits of Capitalism. London, England: Routledge.

Wolf, E. (1982). Europe and the People without History. Berkeley: University of California Press.
Conflict of Interest: The author declares that the research was conducted in the absence of any commercial or financial relationships that could be construed as a potential conflict of interest.

Publisher's Note: All claims expressed in this article are solely those of the authors and do not necessarily represent those of their affiliated organizations, or those of the publisher, the editors and the reviewers. Any product that may be evaluated in this article, or claim that may be made by its manufacturer, is not guaranteed or endorsed by the publisher.

Copyright $\odot 2021$ Eriksen. This is an open-access article distributed under the terms of the Creative Commons Attribution License (CC BY). The use, distribution or reproduction in other forums is permitted, provided the original author(s) and the copyright owner(s) are credited and that the original publication in this journal is cited, in accordance with accepted academic practice. No use, distribution or reproduction is permitted which does not comply with these terms. 